\title{
Anaesthetic management of omphalopagus twins for Non-Operating-Room-Anaesthesia
}

\author{
S. Vergine, A. Benigni, D. Bonacina, M. Maffioletti, E. Bonanomi, F.L. Lorini \\ University of Brescia and Papa Giovanni XXIII Hospital Bergamo, Italy
}

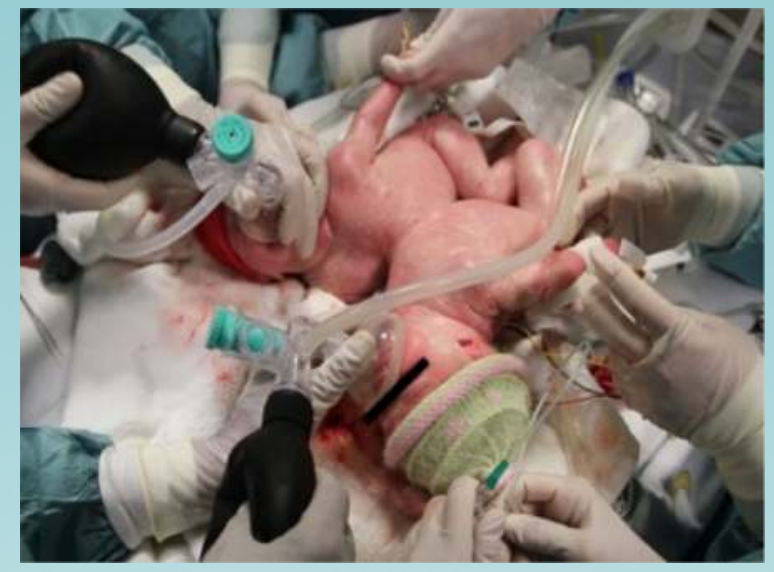

Abdominal connection of twins

\section{BACKGROUND}

Three-month-old conjoined female omphalopagus twins weighing $8.4 \mathrm{~kg}$ underwent preoperative SPECT/CT. The twins had shared liver and apparently only one gallbladder at previous abdominal ultrasound.

\section{CASE REPORT}

According to the experience in few cases $^{1}$, our anaesthetic team included two anaesthesiologists and two nurses, each twin had her own equipment. Two laryngoscopies, two orotracheal tubes, two monitors and two separate sources of oxygen were secured and the drugs were color coded to each twin.

The babies were called T1 and T2 to avoid confusion. Before the procedure, accurate clinical examination of the twins was performed. The anatomical connection under the xyphoid process and the absence of head or neck abnormalities made the airways simultaneously approachable by two anaesthesiologists. Sedation in spontaneous breathing was considered safe for a one-hour procedure.

Two separate venous lines were cannulated, one for each twin, i.v. propofol was administered ( $3 \mathrm{mg} / \mathrm{kg}$ ) to $\mathrm{T} 1$.

No significant change in consciousness was observed in T2, suggesting little cross-circulation. T2 was also induced and i.v. continuous propofol was set at $7 \mathrm{mg} / \mathrm{kg} / \mathrm{h}$ for each twin to ensure stillness and to preserve spontaneous breathing. At the end of investigation, both infants were transferred to the paediatrics ward awake and eupnoeic.

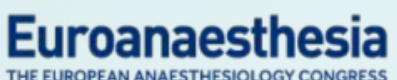

\section{DISCUSSION}

The conjoined twins are a rare anomaly and every pair of twins has unique anatomical and physiological peculiarity: few centres in the world ${ }^{1,2,3}$ reported experiences about their anaesthetic management. We decided to set up a sedation in spontaneous breathing, considering the favourable anatomical configuration for access to the airway and duration of procedure. Moreover, the anaesthetic team, the equipment and the radiological room were carefully provided for contemporary management of two patients.

\section{LEARNING POINTS}

Non-Operating-Room-Anaesthesia in conjoined twins should be planned in an appropriate context. They may assume a wide range of anatomical configurations that requires carefulness in airway evaluation and management; furthermore, the radiological room should be adequately scheduled to contain the duplicated anaesthetic team and equipment.

\section{REFERENCES}

1) Stuart et al. Seminars in Paediatric Surgery 2015, 24: 224-8

2) Thomas et al. Paediatric Anaesthesia 2004, 14:117-29

3) Cumming et al. NEJM 2017, 377: 1667-77

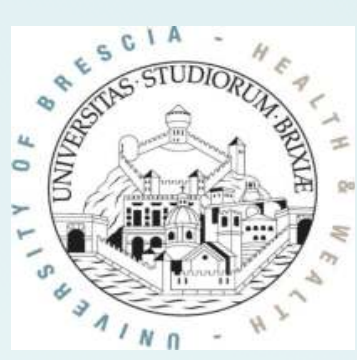

Azienda Ospedaliera Papa Giovanni XXIII 